Pesq. Vet. Bras. 36(10):965-970, outubro 2016 DOI: 10.1590/S0100-736X2016001000008

\title{
Identificação de transcritos diferencialmente expressos por Pasteurella multocida em condições de privação de ferro ${ }^{1}$
}

\author{
Mayara I.V. Silva ${ }^{2}$, Cristiane S. Chitarra², João X. de Oliveira Filho ${ }^{3}$, Nelson Morés ${ }^{3}$, \\ Alessandra Tammy Hayakawa Ito ${ }^{2}$, Icaro Sergio Magalhães Rocha², Luciano \\ Nakazato ${ }^{2}$ e Valéria Dutra ${ }^{2 *}$
}

\begin{abstract}
Silva M.I.V., Chitarra C.S., Oliveira Filho J.X., Morés N., Ito A.T.H., Rocha I.S.M., Nakazato L. \& Dutra V. 2016. [Identification of differentially expressed transcripts by Pasteurella multocida iron-starved condition.] Identificação de transcritos diferencialmente expressos por Pasteurella multocida em condições de privação de ferro. Pesquisa Veterinária Brasileira 36(10):965-970. Laboratório de Microbiologia e Biologia Molecular Veterinária, Universidade Federal do Mato Grosso, Av. Fernando Corrêa da Costa 2367, Bairro Boa Esperança, Cuiabá, MT 78060-900, Brazil. E-mail: valdutra@ufmt.br

Iron ( $\mathrm{Fe}$ ) is an essential element and the ability to acquire it in vivo has been described in several pathogens as virulence factors. Global analyses of transcripts during iron deprivation have been described by microarray studies, however recently RNA-seq analysis showed superior results. The high pathogenic swine strain of Pasteurella multocida (BRMSA 1113) was grown in two conditions with different concentrations of Fe (control and deprivation) in order to analyze the differentially expressed transcripts. The total RNA of the two conditions was extracted and sequenced by new generation Ion Torrent plataform. Data were analyzed in Ion Reporter ${ }^{\mathrm{TM}}$ Software and processed in Rockhopper software. Sequence analysis shows 1,341,615 readings with median length of $81 \mathrm{pb}$, with $96 \%$ of alignment to the reference genome Pasteurella multocida strain 3489 , and $98.8 \%$ accuracy. Reads mapping to genome of $P$. multocida in these two conditions detected 2,652 transcripts, which 177 (6.7\%) were differentially expressed, with 93 in the control condition $(\mathrm{Fe}+)$ and 84 provided with iron deprivation condition (Fe-). In condition (Fe-), differential expressed transcript profile were associated to function of cellular transport (fbpABC, high-affinity $\mathrm{Fe}^{2+} / \mathrm{Pb}^{2+}$ permease and periplasmic protein probably involved in hight-affinity $\mathrm{Fe}^{2+}$ ), transcptional regulators and hypothetical proteins. The control condition ( $\mathrm{Fe}+$ ) shows differential expressed transcripts profile associated to RNA anti-sense (asRNA) energetic metabolism genes (fructose-1,6-bisphosphatase). The study showed that the Fe restriction increases the expression of genes involved in cellular transport, transcriptional regulators, hypothetical and unknown proteins, and also allowed the identification of High-affinity $\mathrm{Fe}^{2+} / \mathrm{Pb}^{2+}$ permease e Periplasmic protein probably involved in high-affinity $\mathrm{Fe}^{2+}$, that constitute a possible alternative route for $\mathrm{Fe}$ absorption.
\end{abstract}

INDEX TERMS: Pasteurella multocida, pasteurellosis, gene expression, Fe deprivation, RNA-seq, new generation sequencing.

\footnotetext{
${ }^{1}$ Recebido em 7 de Agosto de 2015.

Aceito em 25 de Junho de 2016.

${ }^{2}$ Laboratório de Microbiologia e Biologia Molecular, Departamento de Clínica Médica Veterinária, Hospital Veterinário, Universidade Federal de Mato Grosso (UFMT), Av. Fernando Corrêa da Costa 2367, Bairro Boa Esperança, Cuiabá, MT 78060-900, Brasil. *Autor para correspondência: valdutra@ufmt.br

${ }^{3}$ Embrapa Suínos e Aves, Rodovia BR153 Km 110, Distrito de Tamanduá, Cx. Postal 21, Concórdia, SC 89700-000, Brasil.
}

RESUMO.- Ferro (Fe) é um elemento essencial e a capacidade de adquiri-lo in vivo têm sido descrita em diversos agentes patogênicos através de fatores de virulência. Análises de transcritos durante a privação de Fe tem sido descritos através da técnica de "microarray", entretanto a técnica de RNA-seq recentemente tem demonstrado resultados superiores. Neste trabalho, o isolado de Pasteurella multocida (Pm 16759) altamente patogênico em suínos foi cultivado 
em duas condições com diferentes concentrações de $\mathrm{Fe}$ (controle e privação) com o objetivo de analisar transcritos diferencialmente expressos. O RNA total das duas condições foi extraído e sequenciado através da plataforma de nova geração Ion Torrent. Os dados foram analisados no Software Ion Reporter ${ }^{\mathrm{TM}}$ e processados no programa Rockhopper. Foram obtidas 1.341.615 leituras com tamanho médio de $81 \mathrm{pb}$, com $96 \%$ de alinhamento com o genoma de Pasteurella multocida subsp. multocida 3480 e 98,8\% de acurácia. No mapeamento das leituras das duas condições, observou-se 2,652 transcritos e destes, 177 (6,7\%) foram diferencialmente expressos, sendo 93 na condição controle ( $\mathrm{Fe}+$ ) e 84 na condição de privação (Fe-). Na condição de privação de $\mathrm{Fe}$, o perfil de transcritos foram associados a função de transporte celular $(\mathrm{fbp} A B C$, permease de alta afinidade com $\mathrm{Fe}^{2+} / \mathrm{Pb}^{2+}$ e proteína periplasmática de alta afinidade com $\mathrm{Fe}^{2+}$ ), reguladores transcricionais e proteínas hipotéticas. 0 perfil na condição controle ( $\mathrm{Fe}+$ ) apresentou transcritos diferencialmente expressos associados ao RNAs anti-sense (asRNA) e genes do metabolismo energético (fructose-1,6-bisfosfatase). 0 estudo comprovou que a restrição de Fe aumenta a expressão de genes envolvidos no transporte celular, reguladores transcricionais, proteínas hipotéticas e desconhecidas e permitiu ainda a identificação de novos genes como a permease de alta afinidade com $\mathrm{Fe}^{2+} / \mathrm{Pb}^{2+}$ e proteina periplasmática de alta afinidade com $\mathrm{Fe}^{2+}$, que configuram uma possível via alternativa de absorção de Fe.

TERMOS DE INDEXAÇÃO: Pasteurella multocida, pasteurelose, expressão gênica, privação de Fe, RNA-seq, sequenciamento de nova geração.

\section{INTRODUÇÃO}

Pasteurella multocida (P. multocida) é um cocobacilo gram-negativo, pertencente à família Pastereullaceae e é classificada de acordo com a cápsula de polissacarídeo (A, B, D, E e F) e antígenos somáticos (1-16) (Harper et al. 2014). $P$. multocida é um importante agente patogênico responsável por causar doença em diversas espécies de hospedeiros, tais como a cólera aviária em galinhas e perus, septicemia hemorrágica em bovinos e bubalinos (Harper et al. 2006, Petersen et al. 2014), pneumonia, rinite atrófica e septicemia em suínos (Pijoan 2006, Ujvári et al. 2015) e septicemia em humanos (Collins et al. 2012, Nagata et al. 2013, Narsana \& Farhat 2015). Embora a P. multocida raramente ocasione a morte de animais, o problema respiratório gerado por sua infecção leva a redução do ganho de peso acarretando expressivas perdas econômicas (Conceição \& Dellagostin 2006, Shivachandra et al. 2014).

Estudos sobre a proliferação de bactérias e fungos no tecido do hospedeiro têm demonstrado que seu crescimento é limitado não só por mecanismos de defesa do hospedeiro, mas também pela disponibilidade de nutrientes, como o Ferro ( $\mathrm{Fe}$ ), importante fator de crescimento que participa de processos biológicos essenciais como transporte de oxigênio, regulação gênica e síntese de DNA (Escolar et al. 1999, Paustian et al. 2001, Paustian et al. 2002, Madigan et al. 2010, Ding et al. 2014). A necessidade de Fe e a capacidade de adquiri-lo in vivo têm sido descrita em diversos agentes patogênicos como fatores de virulência (Lee et al. 2007).

Em bactérias patogênicas, um dos fatores que desencadeiam a infecção e consequentemente a sua colonização é a privação de Fe quando em contato com o hospedeiro, pois a quantidade de Fe livre é estritamente limitada e geralmente ligada a proteínas, tais como transferrina, lactoferrina e ferritina (Denner \& Potter1989, Stuchi 2012). P. multocida, assim como outras bactérias, desenvolveu mecanismos básicos para adquirir Fe através de agentes quelantes (sideróforos) que captam o Fe de hidróxidos férricos ou por receptores a partir de proteínas do hospedeiro (Jacques et al. 1994, Wilson \& Ho 2013). 0 sequenciamento do genoma de P. multocida Pm70 revelou que 2,5\% do genoma da bactéria correspondem a 53 proteínas codificadas similares às envolvidas no metabolismo do Fe (May et al. 2001).

Até recentemente a análise de transcritos expressos por patógenos de interesse médico eram baseados apenas em técnicas de microarray, o que vem sendo complementado e melhorado pelas técnicas de sequenciamento de nova geração (Paustian et al. 2001, Paustian et al. 2002, Kogenaru et al. 2012).

O presente estudo teve como objetivo avaliar a resposta transcricional de genes bacterianos frente a privação de $\mathrm{Fe}$, semelhante ao ocorrido durante o processo de infecção, através de sequenciamento de nova geração, permitindo maior entendimento da patogenia da doença e consequente auxilio na prevenção e tratamento mais eficaz das pasteureloses.

\section{MATERIAL E MÉTODOS}

Isolado bacteriano e delineamento experimental. 0 isolado de Pasteurella multocida (Pm 16759), sorotipo A foi obtido de uma lesão de pleuropneumonia fibrinonecrossupurativa focalmente extensa acentuada de um suíno livre de patógeno específico (Specific Pathogen Free - SPF), previamente inoculado com a cepa BRMSA 1113 no estudo realizado por Oliveira Filho et al. (2015).

Condições de cultivo. Inicialmente, o pré-inóculo foi cultivado em $3 \mathrm{ml}$ de caldo infusão cérebro e coração (Brain Heart Infusion - BHI) e incubado a $37^{\circ} \mathrm{C}$ por $18 \mathrm{~h}$. Posteriormente adicionouse $180 \mathrm{ml}$ de caldo $\mathrm{BHI}$ e incubou-se à $37^{\circ} \mathrm{C}$ sob agitação $(60 \mathrm{rpm})$ por quatro horas e trinta minutos até atingir 0,7 na $\mathrm{DO}_{600 \mathrm{~nm}}$. Em seguida, o caldo foi dividido em duas alíquotas de $90 \mathrm{ml}$, que foram então centrifugadas à $1000 \mathrm{~g}$ por 30 minutos para formação de sedimento (pellet), que foram lavados com tampão fosfato-salino (phosphate buffered saline - PBS) 1\% e ressuspendidos em 180 mL de caldo BHI. Para a condição de restrição de Fe (Fe-) foi adicionado ao meio o quelante $2,2^{\prime}$-bipyridyl, na concentração de $0,150 \mathrm{mM}$ e incubados a $37^{\circ} \mathrm{C}$ com agitação por 60 minutos . A condição sem adição do quelante $(\mathrm{Fe}+)$ foi considerada como controle (Paustian et al. 2001).

Extração de RNA. O RNA total das duas condições foi extraído usando o protocolo descrito por Sambrook \& Russel (2004), posteriormente tratados com a enzima DNAse I (Fermentas ${ }^{\mathrm{TM}}$ ) e com RiboMinus $^{\mathrm{TM}}$ Bacteria Transcriptome Isolation Kit (Invitrogen ${ }^{\mathrm{TM}}$ ), conforme instrução do fabricante para remoção de DNA genômico e RNA ribossômico.

Sequenciamento em Ion Torrent. Os produtos de RNA extraídos das populações em cada condição de cultivo (Fe+ e Fe-) foram fragmentados usando a enzima RNAse III (Ion RNA-Seq 
Core Kit v2, 12-Reaction Kit - Life Technologies ${ }^{\mathrm{TM}}$ ) e imediatamente purificados com o Kit Magnect Bead Cleanup Module (Life Technologies $^{\mathrm{TM}}$ ), quantificados por kit Qubit RNA High Sensivite (Life Technologies ${ }^{\mathrm{TM}}$ ) e então checados no Bioanalyzer (Agilent Technologies ${ }^{\mathrm{TM}}$ ). Em seguida, as amostras foram hibridizadas e então ligadas ao adaptador Ion Adapter Mix V2 e submetidas à Transcrição Reversa para a síntese do DNA complementar (cDNA), purificadas e então amplificadas. Essas etapas foram conduzidas utilizando o Ion Total RNA-seq Kit V2. Para indexação das amostras e amplificação da biblioteca foi utilizado o Kit Ion Xpress $^{\mathrm{TM}}$ RNA-Seq Barcode. Após a amplificação todas as amostras foram quantificadas no Qubit RNA HS e padronizadas na mesma concentração. A PCR de emulsificação foi realizada utilizando o Ion OneTouch ${ }^{\mathrm{TM}} 2$ System (Life Technologies ${ }^{\mathrm{TM}}$ ), seguindo as normas de inicialização e calibragem do fabricante, utilizando o Ion PGM ${ }^{\mathrm{TM}}$ Template OT2 200 Kit. O sequenciamento foi realizado no Ion PGM ${ }^{\text {TM }}$ System usando o Ion $318^{\text {TM }}$ Chip v2 e o Ion PGM ${ }^{\text {TM }}$ Sequencing 200 Kit.

Processamento dos dados. 0 programa Rockhopper ${ }^{\circledR}$ foi utilizado para análise dos dados do sequenciamento seguindo as instruções do desenvolvedor (Tjaden 2015). As sequências das amostras em condição $\mathrm{Fe}+$ e Fe- foram alinhadas e mapeadas com o genoma de Pasteurella multocida subsp. multocida str. 3480 (GenBank NC_017764.1). Utilizaram-se duas estimativas da variância de expressão e, em seguida, executou-se um teste estatístico para determinar se o transcrito tem expressão diferencial em duas condições, calculando-se "pValue" que indica essa probabilidade. Estes foram corrigidos pelo procedimento Benjamini-Hochberg para obtenção dos valores de qValue. Considerou-se diferencialmente expressos genes que apresentaram qValue entre zero e 0,01. A classificação funcional dos transcritos foi obtida através do banco de dados Kyoto Enciclopédia de Genes e Genomas (Kyoto Encyclopedia of Genes and Genomes - KEGG).

Síntese da primeira fita de cDNA. A reação de transcrição reversa foi realizada utilizando 750ng de RNA total das duas condições de cultivo ( $\mathrm{Fe}+\mathrm{e}$ Fe-), Randon Primer (Sambrook \& Russel 2004), enzima M-MLV transcriptase reversa (Invitrogen) e DTT $0.1 \mathrm{M}$ (Invitrogen). A ordem e as etapas de incubação foram realizadas de acordo com as recomendações do fabricante.

Transcriptase reverse quantitative polymerase chain reaction (RT-qPCR). Para a análise de RT-qPCR foram selecionados nove transcritos diferencialmente expressos, com qValue positivo mais próximo de zero, e um gene controle endógeno, com

Quadro 1. Genes diferencialmente expressos e gene normalizador selecionados para realização do RT-qPCR

\begin{tabular}{|c|c|c|}
\hline \multicolumn{3}{|c|}{ Genes diferencialmente expressos } \\
\hline Locus tag & Gene & qValue \\
\hline NT08PM_2244 & 3-dehidroquinato sintetase & 7.988740364664123-7 \\
\hline NT08PM_0862 & $\begin{array}{c}\text { Permease de alta afinidade } \\
\text { com } \mathrm{Fe} 2+/ \mathrm{Pb} 2+\end{array}$ & $2.6223417380407115-4$ \\
\hline NT08PM_0609 & $\begin{array}{l}\text { Ferritina contendo Ferro de } \\
\text { origem não hemica }\end{array}$ & $4.26956153985527-5$ \\
\hline NT08PM_0863 & $\begin{array}{c}\text { Proteína periplasmática } \\
\text { de transporte de alta } \\
\text { afinidade com } \mathrm{Fe} 2+\end{array}$ & $8.3557096185621-8$ \\
\hline NT08PM_0913 & AfeA & $1.276604369360765-6$ \\
\hline NT08PM_1342 & FbpA & $3.292282860269677-34$ \\
\hline NT08PM_1343 & $F b p B$ & 1 \\
\hline NT08PM_1344 & $\mathrm{FbpC}$ & 1 \\
\hline NT08PM_2004 & $\begin{array}{c}\text { Provável oxidase } \\
\text { coproporfirogenio III } \\
\text { oxigênio-independente }\end{array}$ & $5.551789007198091-6$ \\
\hline \multicolumn{3}{|c|}{ Gene controle endógeno } \\
\hline
\end{tabular}

qValue igual a um (Quadro 1). Os primers utilizados foram obtidos através da análise das sequências depositadas no Centro Nacional de Informação Biotecnológica (National Center for Biotechnology Information - NCBI) a partir do genoma completo de Pasteurella multocida subsp. multocida str. 3480 (GenBank NC_017764.1) (Quadro 2). Para validação dos transcritos expressos, a reação da primeira fita do cDNA foi submetida a análises por RT-qPCR, utilizando-se mistura SYBR green qPCR mix (Applied Biosystems, Foster City, CA) no sistema Step One real-time PCR system (Applied Biosystems Inc.). As reações foram realizadas em triplicata para cada amostra de cDNA e os níveis de expressão relativa dos transcritos foram calculados utilizando-se o método de $2^{-\Delta \Delta C t}$ (Bookout et al. 2006). Para identificar diferenças dos níveis de expressão de cada gene submetido ao RT-qPCR entre os tratamentos (Fe+ e Fe-) foi aplicado o teste de $t$-Student admitindo-se como níveis de significância valores de $p \leq 0.05$.

Quadro 2. Primers ultilizados na amplificação dos genes diferencialmente expressos e gene controle endógeno na técnica de RT-qPCR

\begin{tabular}{|c|c|}
\hline \multicolumn{2}{|c|}{ Genes diferencialmente expressos } \\
\hline Gene & Primers \\
\hline 3-dehidroquinato sintetase & $\begin{array}{l}\text { 5'- AGCGTACACAGCGTGATAAA -'3 } \\
\text { 5'- TCGGCAATTTCTTCATACAAAGG -3 }\end{array}$ \\
\hline Permease de alta afinidade & 5'- GCGAGCTGATTTGCTTGTTG -3' \\
\hline $\mathrm{com} \mathrm{Fe} 2+/ \mathrm{Pb} 2+$ & 5'- AAGCTGAACTCGAAGGCTATTT -3' \\
\hline Ferritina contendo Ferro de origem & 5'- TCATCAGCATGGCGTAAAAG -3' \\
\hline não hemica & 5'- CAACGGAAAGGGGTCAGTTA -3' \\
\hline \multicolumn{2}{|c|}{$\begin{array}{l}\text { Proteína periplasmática de transporte 5'- ACACCAGTTTCTTCATCGGTAT -3' } \\
\text { de alta afinidade com Fe2+ }\end{array}$} \\
\hline \multirow{3}{*}{ 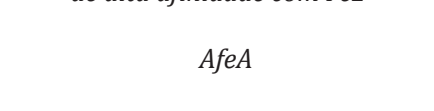 } & 5'- TGGTCCACACTATGGCTTAAAT -3' \\
\hline & 5'- TTGTTGTGGTGTGCCTTGTT -3' \\
\hline & 5'- TGCCAAAATTCCTGAAGGTC -3' \\
\hline \multirow[t]{2}{*}{ FbpA } & 5'- AAAGCCAATGCGGTGAAATTAG -3' \\
\hline & 5'- CTGGGTACTCATGGTTCAACTC -3' \\
\hline \multirow[t]{2}{*}{$F b p B$} & 5'- CGGTGATCGCTTCTGTTGTA -3' \\
\hline & 5'- CCGAGGGAGGAAAGTTGTAAG -3' \\
\hline \multirow[t]{2}{*}{$\mathrm{FbpC}$} & 5'- TCCAACGGGAAGCCAATAAG -3' \\
\hline & 5'- TTCCACTGCCTTGCTCAT C-3' \\
\hline \multirow{2}{*}{\multicolumn{2}{|c|}{$\begin{array}{l}\text { Provável oxidase coproporfirogenio III 5'- CGCTTCTTCTAAGGTCTGGTTAG -3' } \\
\text { oxigênio-independente }\end{array}$}} \\
\hline & \\
\hline \multicolumn{2}{|c|}{ Gene controle endógeno } \\
\hline Transaldolase & 5'- GACGGTTGTTGTCGCAGATA -3' \\
\hline & 5'- GGCGTGGACAATCACTTTTT -3' \\
\hline
\end{tabular}

\section{RNA-seq}

\section{RESULTADOS}

A análise dos dados através do Software Ion Reporter ${ }^{\mathrm{TM}}$ resultou em 1,341,615 leituras, sendo 583,217 na condição com tratamento (Fe-) e 758,217 na condição controle $(\mathrm{Fe}+)$. 0 tamanho médio das sequências foram de 81 pares de base (pb), com amplitude de 86 pb a 118 pb. As sequências das duas bibliotecas apresentaram um alinhamento de 96\% com o genoma de referência e 98,8\% de acurácia.

Foram mapeados no genoma de $P$. multocida nas duas condições 2,652 transcritos, destes 177 (6,7\%) foram diferencialmente expressos, sendo 93 na condição controle $(\mathrm{Fe}+)$ e 84 na condição com tratamento (Fe-).

Na condição com privação de Fe, foram diferencialmente expressos 20 genes (Quadro 3), 8 proteínas hipotéticas, 26 antisenses e 30 RNAs preditivos. Na condição Fe+ foram 
Quadro 3. Genes diferencialmente expressos de P. multocida nas condições de tratamento (Fe-) e controle ( $\mathrm{Fe}+$ ) com base na análise de dados do sequenciamento pelo Ion Torrent

\begin{tabular}{|c|c|c|}
\hline \multicolumn{3}{|c|}{ Genes diferencialmente expressos na condição Fe- } \\
\hline Locus tag & Transcritos & qValue \\
\hline NT08PM_0596 & Proteína OppA & 0.0031399542654867774 \\
\hline NT08PM_0398 & Tetraacildisaccaride 4'-kinase & 0.0015660821716683327 \\
\hline NT08PM_2244 & 3-dehidroquinato sintetase & 7.988740364664123-7 \\
\hline NT08PM_0739 & $\begin{array}{c}\text { Sistema de liberação } \\
\text { de lipoproteínas, Proteina } \\
\text { de ligação de ATP }\end{array}$ & 0.0 \\
\hline NT08PM_1353 & $\begin{array}{l}\text { Transportador } A B C \text { de } \\
\text { proteína de ligação com ATP }\end{array}$ & $2,25-3$ \\
\hline NT08PM_0862 & $\begin{array}{c}\text { Permease de alta afinidade } \\
\mathrm{Fe} 2+/ \mathrm{Pb} 2+\end{array}$ & $2.6223417380407115-4$ \\
\hline NT08PM_0886 & Excinuclease $A B C$ subunidade $B$ & 0.001398156 \\
\hline NT08PM_0609 & Ferritina contendo ferro não hemic & co $4.26956153985527-5$ \\
\hline NT08PM_0920 & Proteína $Y c c F$ & 0.08880683713271024 \\
\hline NT08PM_0933 & $\begin{array}{c}\text { Proteina RnfG de transporte } \\
\text { de eletrons }\end{array}$ & 0.0 \\
\hline NT08PM_1125 & Proteína recombinante $\operatorname{Rec} R$ & 0.0 \\
\hline NT08PM_1147 & $\begin{array}{l}\text { Provável Sintase 6-piruvoil } \\
\text { tetrahidrobiopterina }\end{array}$ & 0.004336800435606551 \\
\hline NT08PM_0863 & $\begin{array}{l}\text { Proteína periplasmática de } \\
\text { transporte de alta } \\
\text { afinidade com } \mathrm{Fe} 2+\end{array}$ & $8.3557096185621-8$ \\
\hline NT08PM_0913 & AfeA & $1.276604369360765-6$ \\
\hline NT08PM_1342 & FbpA & 3.292282860269677-34 \\
\hline NT08PM_1343 & $F b p B$ & 1 \\
\hline NT08PM_1344 & $\mathrm{FbpC}$ & 1 \\
\hline NT08PM_1536 & $\mathrm{NapF}$ & 0.0 \\
\hline NT08PM_1974 & Provável superfamília de ciclases & 0.0 \\
\hline NT08PM_2004 & $\begin{array}{c}\text { Provável oxidase } \\
\text { coproporfirogenio III } \\
\text { oxigênio-independente }\end{array}$ & 5.551789007198091-6 \\
\hline
\end{tabular}

Genes diferencialmente expressos na condição Fe+

NT08PM_0353

NT08PM_0543

NT08PM_0661

NT08PM_0900

NT08PM_0987

NT08PM_1270

NT08PM_1367

NT08PM_1370

NT08PM_1387

NT08PM_1389

NT08PM_1447

NT08PM_1601

NT08PM_1602

NT08PM_1634

NT08PM_1684

NT08PM_1776

NT08PM_1801

NT08PM_1930

NT08PM_1934

NT08PM_2118

NT08PM_2192

Proteina MutL

Fosfatidilglicerol fosfatase $A$

tRNA pseudouridina sintase $A$

Heparosano sintase $B$

Proteína OmpW

Beta-hexosaminidase NrfD

Nitrito redutase (citocromo, formando amónia)

Proteína CcmB Heme-exportadora

Proteína de resistência

à Biciclomicina

3-isopropilmalato

desidratase subunidade grande

Chaperone proteína TorD

Redutase TorA

Proteina DmsB

Proteina FbaA

Cátions Férricos importadores

de ATP-vinculativo proteína FbpC

Frutose-1,6-bisfosfatase

Nitrato redutase periplasmática, subunidade grande Proteína NapC

Regulador transcricional da família UfpA

Proteína LsrR

0.0

0.004223117841529832

0.0

0.0040393278870247875

0.0

0.0

0.0

0.0

0.0

0.0

0.0

0.0

0.0

0.0

0.0

0.0

0.0

0.0

0.0

0.0

0.0

considerados diferencialmente expressos 21 genes (Quadro 3), 4 proteínas hipotéticas, 62 antisenses e 6 RNAs preditivos, distribuídas de acordo sua função (Fig.1). Observou-se na condição $\mathrm{Fe}+$ um aumento de antisense e genes associados ao metabolismo energético como o $d m s B$ (NT08PM). Na

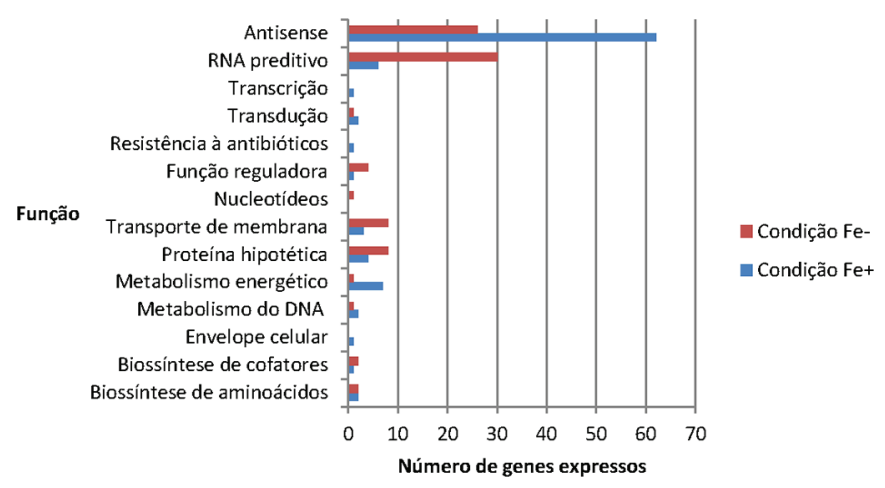

Fig.1. Distribuição de genes diferencialmente expressos de acordo com função e expressão nas condições de cultivo $\mathrm{Fe}+\mathrm{e} \mathrm{Fe}$-.

condição Fe-, por outro lado, houve aumento nos níveis de genes envolvidos no transporte celular, reguladores transcricionais, proteínas hipotéticas e desconhecidas.

\section{RT-qPCR}

Todos os genes selecionados apresentaram aumento da expressão na condição Fe-, com exceção dos genes $f b p B$ e $f b p C$, que obtiveram maior expressão na condição $\mathrm{Fe}+(\mathrm{RQ}$ $f b p B=0,9280$ e $\mathrm{RQ} f b p C=0,8100)$ e os genes 3-dehidroquinato sintetase $(\mathrm{RQ}=1,0344)$ e Provável oxidase coproporfirogenio III oxigênio-independente $(\mathrm{RQ}=0,8908)$ que foram igualmente expressos nas duas condições. Os genes Proteína periplasmática de transporte de alta afinidade com $\mathrm{Fe}^{2+}$ $(\mathrm{RQ}=9,8499)$, fbpA $(\mathrm{RQ}=10,8055)$, Ferritina contendo Ferro de origem não hemica $(\mathrm{RQ}=1,6764)$, Permease de alta afinidade com $\mathrm{Fe}^{2+} / \mathrm{Pb}^{2+}(\mathrm{RQ}=3,7484)$ e AfeA $(\mathrm{RQ}=3,7834)$, tiveram maior expressão na condição Fe- (Fig.2).

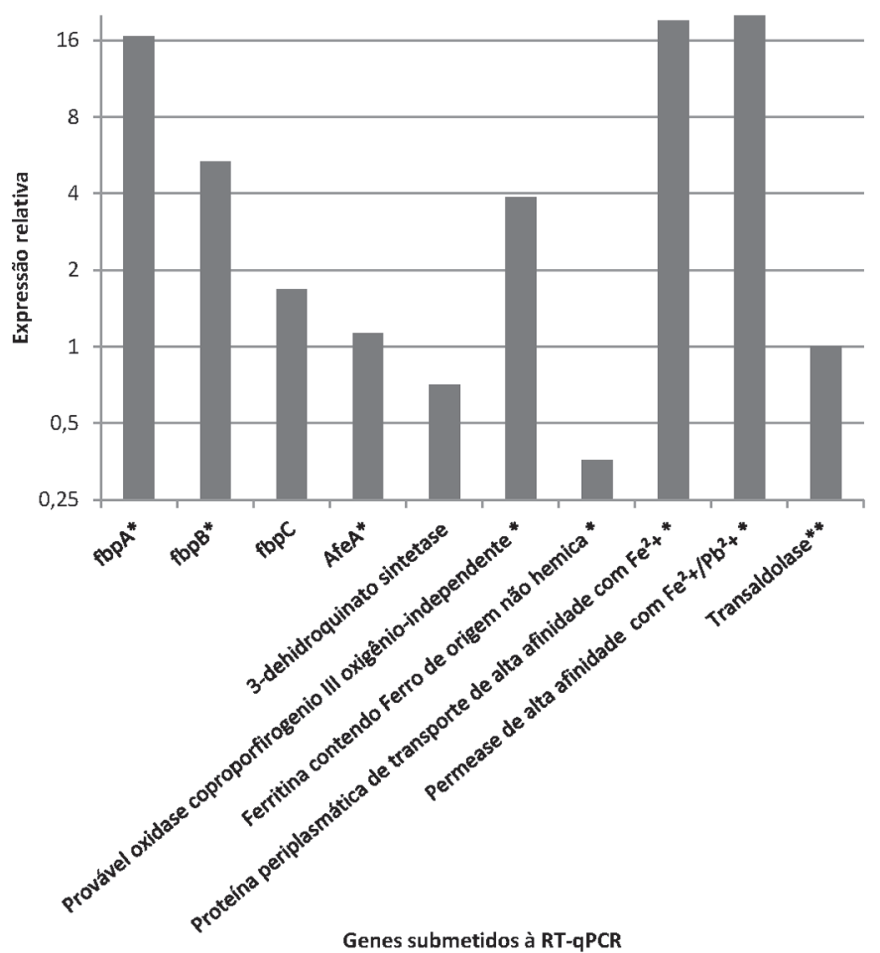

Fig.2. Expressão relativa dos genes submetidos a RT-qPCR na condição de tratamento (Fe-). $\left({ }^{*} \mathrm{p} \leq 0,05\right.$; **gene de controle endógeno). 


\section{DISCUSSÃO}

No presente trabalho foram mapeados 2,652 transcritos no genoma de Pasteurell multocida, sendo 177 diferencialmente expressos enquanto que no estudo desenvolvido por Paustian et al. (2001) foram identificados 1.936 Open Reading Frames (ORFs) pela técnina de microarranjo, com 135 genes diferencialmente expressos. Destes, $55,55 \%$ foram identificados em nosso estudo, porém, apenas um deles $(f b p A)$ apresentou-se diferencialmente expresso. Essa diferença pode ser atribuída a diferença entre as técnicas, pois RNAseq apresenta menor "background" com alta reprodutibilidade e resolução (Kogenaru et al. 2012).

0 perfil de transcritos superexpressos na condição de $\mathrm{Fe}^{-}$está associado a transoporte celular e proteínas de membrana que são descritos em $P$. multocida e outras bactérias. Os genes da família $f b p A B C$, por exemplo, durante a privação de Fe em bactérias estão associados ao complexo tonB (Paustian et al. 2001, Paustian et al. 2002), que captura o Fe3+ da trasferrina para o espaço periplasmático bacteriano (Armstrong et al. 2012). Estudos de expressão dos genes fbpABC em Neisseria miningitidis, demostraram que a transcrição de $f b p A$ é aumentada em condições de limitação de $\mathrm{Fe}$, além da interação acoplada de $f b p A B$ e $f b p B C$ no transporte de Fe periplasmático de transferrina e lactoferrina humana. No entanto, a participação obrigatória de $f b p C$ permanece incerta (Khun et al. 2000), sendo esse o provável motivo da baixa expressão desse gene em privação de Fe, detectada em nosso estudo.

Além de genes relacionados diretamente a absorção e transporte de Fe, também se observou na condição de tratamento (Fe-) o gene Ferritina contendo Fe de origem não hemica, uma oxiredutase capaz de formar esferas de armazenamento de átomos de $\mathrm{Fe}$, tornando-os assim disponíveis para a célula além de protegê-la dos efeitos tóxicos de acúmulo de Fe, sendo esse resultado similar aos encontrados por outros autores em P. multocida (Paustian et al. 2002) e Helicobacter pylori (Huang et al. 2009) cultivada em meios com privação de Fe.

Permease de alta afinidade com $\mathrm{Fe}^{2+} / \mathrm{Pb}^{2+}$ e Proteína periplasmática de transporte de alta afinidade com $\mathrm{Fe}^{2+}$ são proteínas de vias alternativas de absorção de Fe a partir de transferrina, independente do complexo ton $B$. A sequência do gene que codifica essa permease apresenta homologia ao gene FRT1 pertencente ao genoma de alguns fungos, como o Saccharomyces cerevisiae e Candida albicans, (Ding et al. 2014) que codifica uma permease que capta o $\mathrm{Fe}^{3+}$ diretamente para o citoplasma do agente, mas que até então não havia sido descrita por outros autores em experimentos de avaliação de resposta transcricional em condições limitantes de Fe (Knight et al. 2005, Ding et al. 2014).

0 perfil de transcritos diferencialmente expressos na condição $\mathrm{Fe}+$ estão associados ao metabolismo energético e a RNAs antisense (asRNA), podendo estar relacionado com a atenuação e estabilização da transcrição de outros genes expressos, já que asRNA pode afetar negativamente a expressão de um gene quando estes se encontram em posições convergentes, pois as transcrições se sobrepõem enquanto que, contribui positivamente para a expressão do gene adjacente. Assim, um único transcrito regula a expres- são de dois genes adjacentes que possuam funções opostas, assegurando desse modo que a expressão de um resulta na repressão de outro (Sesto et al. 2013).

\section{CONCLUSÕES}

0 estudo mostrou que a presença de Fe aumenta a expressão de genes de metabolismo energético e genes antisense.

A restrição de $\mathrm{Fe}$ ocasionou aumento no nível de genes envolvidos no transporte celular, reguladores transcricionais, proteínas hipotéticas e desconhecidas.

Outro resultado de grande relevância foi a identificação dos genes Permease de alta afinidade com $\mathrm{Fe}^{2+} / \mathrm{Pb}^{2+} \mathrm{e}$ Proteína periplasmática de transporte de alta afinidade com $\mathrm{Fe}^{2+}$, que configuram uma possível via alternativa de absorção de Fe.

Agradecimentos.- À Coordenação de Aperfeiçoamento de Pessoal de Nível Superior (CAPES), pela concessão da bolsa de Mestrado e ao Conselho Nacional de Desenvolvimento Científico e Tecnológico (CNPq), à Embrapa Suínos e Aves de Concórdia, SC, e a FAPEMAT.

\section{REFERÊNCIAS}

Armstrong S.K., Brickman T.J. \& Suhadolc R.J. 2012. Involvement of multiple distinct Bordetella receptor proteins in the utilization of iron liberated from transferrin by host catecholamine stress hormones. Molecular Microbiology 84:446-462.

Bookout A.L., Cummins C.L., Mangelsdorf D.J., Pesola J.M. \& Kramer M.F. 2006. Throughput Real-Time Quantitative Reverse Transcription PCR. Current Protocols in Molecular Biology 73:1-28.

Collins C., Flanagan B. \& Henning J.S. 2012. An Atypical presentation of a Pasteurella multocida infection following a cat bite: a case report. Cutis 89:269-272.

Conceição F.R. \& Dellagostin O.A. 2006. Etiopatogenia e imunoprofilaxia da pneumonia enzoótica suína. Ciência Rural 36:1034-1042.

Denner H.G. \& Potter A.A. 1989. Effect of iron restriction on the outer membrane proteins of Actinobacillus (Haemophilus) pleuropneumoniae. Infect. Immun. 56:798-804.

Ding C., Festa R.A., Sun T.S. \& Wang Z.Y. 2014. Iron and copper as virulence modulators in human fungal pathogens. Molecular Microbiology 93:1023.

Escolar L., Pérez-Martín J. \& Lorenzo V. 1999. Opening the iron box: transcriptional metalloregulation by the Fur protein. J. Bacteriology 181:6223-6229.

Harper M., Boyce J.D. \& Adler B. 2006. Pasteurella multocida pathogenesis: 125 years after Pasteur. Federation of European Microbiological Societies. FEMS Microbiology Letters 265:1-10.

Harper M., Michael F.S., John M., Steen J., Dorsten V., Parnas H., Vinogradov E., Adler B., Cox A.D. \& Boyce J.D. 2014. Structural analysis of lipopolysaccharide produced by Heddleston serovars 10, 11, 12 and 15 and the identification of a new Pasteurella multocida lipopolysaccharide outer core biosynthesis locus, L6. Glycobiology 0:1-11.

Huang C.H., Lee I.L., Yeh I.J., Liao J.H., Ni C.L., Wu S.H. \& Chiou S.H. 2009. Upregulation of a non-heme iron-containing ferritin with dual ferroxidase and DNA-binding activities in Helicobacter pylori under acid stress. J. Biochemistry 147(4):535-543.

Khun H.H., Deved V., Wong H. \& Lee B.C. 2000. fbpABC Gene Cluster in Neisseria meningitides is transcribed as an operon. Infect. Immun. 68(12):7166-7171.

Knight S.A., Vilaire G., Lesuisse E. \& Dancis A. 2005. Iron acquisition from transferrin by Candida albicans depends on the reductive pathway. Infect. Immun. 73(9):5482-5492.

Jacques M., Kobisch M., Bélanger M. \& Dugal F. 1994. Virulence capsulated and non capsulated isolates of Pasteurella multocida and their adherence to porcine respiratory tract cells and mucus. Infect. Immun. 61:4785-4792. 
Kogenaru S., Yan Q., Guo Y. \& Wang N. 2012. RNA-seq and microarray complement each other in transcriptome profiling. BMC Genomics 13:629.

Lee J., Kim Y. B. \& Kwon M. 2007. Outer membrane protein H for protective immunity against Pasteurella multocida. J. Microbiology 45:179-184.

Madigan M.T., Martinko J.M., Dunlap P.L. \& Clark D.P. 2010. Princípios de genética bacteriana. Microbiologia de Brock 12:278-309.

May B.J., Zhang Q., Li L.L., Paulistian M.L., Whittam T.S. \& Kapur V. 2001. Complete genomic sequence of Pasteurella multocida Pm70. Proc. National Academy of Sciences USA 98:3460-3465.

Nagata H., Yamada S., Uramaru K., Kiyasu Y. \& Kano N. 2013. Acute cholecystitis with bacteremia caused by Pasteurella multocida. Surg. Infect. 15:72-74.

Narsana N. \& Farhat F. 2015. Septic shock due to Pasteurella multocida bacteremia: a case report. J. Med. Case Reports 9:159.

Oliveira Filho J.X., Morés M.A.Z., Rebelatto R., Agnol A.M.D., Plieski C.L.A., Klein C.S., Barcellos D.E.S.N. \& Morés N. 2015. Pasteurella multocida type $A$ as the primary agent of pneumonia and septicemia in pigs. Pesq. Vet. Bras. 35(8):716-724.

Paustian M.L., May B.J., Cao D., Boley D. \& Kapur V. 2002. Transcriptional response of Pasteurella multocida to defined iron sources. J. Bacteriology 184:6714-6720.

Paustian M.L., May B.J. \& Kapur V. 2001. Pasteurella multocida gene expression in response to iron limitation. Infect. Immun. 69:4109-4115.

Petersen A., Bisgaard M., Townsend K. \& Christensen H. 2014. MLST typing of Pasteurella multocida associated with haemorrhagic septicaemia and development of a real-time PCR specific for haemorrhagic septicaemia associated isolates. Vet. Microbiol. 170:335-341.
Pijoan C. 2006. Pneumonic pasteurellosis, p.719-726. In: Straw B.E., D’Allaire S., Mengeling W.L. \& Taylor D.J. (Eds), Disease of Swine. 9th ed. Iowa State University Press, Ames.

Sambrook J. \& Russel D.W. 2004. Molecular Cloning: a laboratory manual. 3rd ed. Cold Spring Harbor Laboratory Press, New York.

Sesto N., Wurtzel O., Archambaud C., Sorek R. \& Cossart P. 2013. The excludon: a new concept in bacterial antisense RNA-mediated gene regulation. Nature Reviews Microbiology 11:75-82.

Shivachandra S.B., Kumar A., Mohanty N.N., Yogisharadhya R., Chacko N., Viswas K.N. \& Ramakrishnan M.A. 2014. Homogeneity of VacJ outer membrane lipoproteins among Pasteurella multocida strains and heterogeneity among members of Pasteurellaceae. Res. Vet. Sci. 96:415421

Stuchi L.P. 2012. Identificação e caracterização de genes do sistema de captação de ferro regulados pelo repressor fur em Klebsiella pneumoniae. Dissertação de Mestrado em Ciências da Saúde, Programa de Pós Graduação Stricto Sensu em Ciências da Saúde, Universidade São Francisco, Bragança Paulista, SP. 67p.

Tjaden B. 2015. De novo assembly of bacterial transcriptomes from RNA-seq data. Tjaden Genome Biology 16:1-10.

Ujvári B., Szeredi L., Pertl L., Tóth G., Erdélyi K., Jánosi S., Molnár T. \& Magyar T. 2015. First detection of Pasteurella multocida type B:2 in Hungary associated with systemic pasteurellosis in backyard pigs. Acta Vet. Hung. 63(2):141-156.

Wilson B.A. \& Ho M. 2013. Pasteurella multocida: from zoonosis to cellular microbiology. Clin. Microbiol. Revs 26:631-655. 